\title{
Effect of Surface Biphilicity on FC-72 Flow Boiling in a Rectangular Minichannel
}

\author{
Akam Aboubakri ${ }^{1,2}$, Vahid Ebrahimpour Ahmadi ${ }^{1,2}$, Suleyman Celik ${ }^{2}$, \\ Abdolali K. Sadaghiani ${ }^{1,2,3}$, Khellil Sefiane ${ }^{4}$ and Ali Kosar ${ }^{1,2,3 *}$
}

${ }^{1}$ Faculty of Engineering and Natural Science, Sabanci University, Istanbul, Turkey, ${ }^{2}$ Sabanci University Nanotechnology and Applications Center (SUNUM), Sabanci University, Istanbul, Turkey, ${ }^{3}$ Center of Excellence for Functional Surfaces and Interfaces for Nano-Diagnostics (EFSUN), Sabanci University, Istanbul, Turkey, ${ }^{4}$ School of Engineering, University of Edinburgh, Edinburgh, United Kingdom

OPEN ACCESS

Edited by:

Qing Hao,

University of Arizona, United States

Reviewed by:

Amy Rachel Betz,

Kansas State University, United States

Titan Chandra Paul,

University of South Carolina Aiken,

United States

Hongzhao Wang,

Hong Kong University of Science and

Technology, Hong Kong SAR, China

*Correspondence:

Ali Kosar

kosara@sabanciuniv.edu

Specialty section:

This article was submitted to Thermal and Mass Transport,

a section of the journal

Frontiers in Mechanical Engineering

Received: 09 August 2021

Accepted: 19 October 2021

Published: 29 October 2021

Citation:

Aboubakri A, Ahmadi VE, Celik S, Sadaghiani AK, Sefiane $K$ and Kosar $A$ (2021) Effect of Surface Biphilicity on

FC-72 Flow Boiling in a

Rectangular Minichannel.

Front. Mech. Eng 7:755580.

doi: $10.3389 /$ fmech.2021.755580
Flow boiling is one of the most effective mechanisms in heat transfer thanks to the latent heat of vaporization. Surface modifications such as mixed-wettability have a considerable effect on the boiling heat transfer performance in terms of enhancement in boiling heat transfer as well as critical heat flux. This study introduces a new method of fabrication of biphilic surfaces, where $\mathrm{C}_{4} \mathrm{~F}_{8}$ (Octafluorocyclobutane) islands are surrounded by silicon. Two different biphilic surfaces were fabricated and compared with the entirely uniform hydrophobic surface taken as a reference,. Each of the biphilic surfaces has three different sections, namely inlet, middle and outlet regions. The first region is mainly hydrophobic (inlet), while the third region is mainly hydrophilic (outlet). The heat transfer coefficients were obtained at different heat fluxes. Compared to the entirely uniform hydrophobic surface, the results show that biphilic surfaces enhance the boiling heat transfer performance by up to $50 \%$. The visualization results revealed that the biphilic surfaces lead to more nucleation sites in the bubbly flow regime and break up the elongated bubbles in the slug flow regime.

Keywords: flow boiling, surface modification, FC-72, biphilic surfaces, functional surfaces

\section{INTRODUCTION}

With the decrease in the size of ICs (integrated circuits) and increase in their power density, new methods for heat dissipation become inevitable to maintain the working temperature below a critical value. Approaches for dissipating the generated power include natural convection (Florio and Harnoy, 2007), single phase heat transfer (Ahmadi and Erden, 20182018; Ahmadi and Erden, 2020), and forced convection combined with phase change (Hashemi and Noie, 2017; Sadaghiani et al., 2017). Boiling, whether pool boiling or flow boiling, is one of the most promising approaches to dissipate generated high powers and obtaining high heat transfer coefficients (HTC) due to both sensible heat transfer as well as latent heat of vaporization.

Surface wettability is one of the most important parameters affecting two-phase heat transfer due to modifications in the three phase contact line as well as the number of active nucleation sites (Basu et al., 2002). Experimental studies proved that hydrophobic substrates provide higher heat transfer coefficients in flow boiling in micro- (Choi et al., 2011; Kim and Lee, 2019) and minichannels (Phan et al., 2011; Zhao et al., 2021) in comparison with hydrophilic ones. Generally, low energy surfaces (hydrophobic) remarkably augment the onset of nucleate boiling and bubble departure, while high energy surfaces (hydrophilic) enhance liquid replenishment and raises the critical heat flux 
(Motezakker et al., 2019; Sadaghiani et al., 2020a; Tan et al., 2021). Therefore, recent studies suggest that surface modification is an effective method to improve heat transfer via phase-change heat transfer including droplet evaporation (Dai et al., 2014; Aboubakri et al., 2020), flow condensation (Chehrghani et al., 2021), flow and pool boiling (Shojaeian and Koşar, 2015). For instance, (Sadaghiani et al., 2020a; Sadaghiani et al., 2020b) studied the effect of artificial cavities on three phase contact line and reported an optimum ratio of diameter to pitch distance, which maximized the heat transfer coefficient in pool boiling. Similarly, it was reported that biphilic surfaces resulted in enhancements of pool boiling heat transfer (Motezakker et al., 2019) and flow boiling heat transfer (Ahmadi et al., 2020). According to Honda and Wei (Honda et al., 2002), micro structures such as micro-roughness and micro-porous coatings significantly facilitated the incipience of boiling, while delaying the CHF (critical heat flux). In another study, (Honda and Wei, 2004) conducted pool boiling experiments with FC-72 on silicon substrates modified by micro-pin-fins and obtained noticeable enhancements in the nucleate boiling regime and critical heat flux. Mixed wettability surfaces could be also achieved with surface modification. As an example, Wang et al. (Wang et al., 2019) investigated the effect of mixed wettability on flow boiling of water and reported that mixed wettability surfaces not only increase the nucleation site density but also ease the bubble departure. In the study of Kim et al. (Kim et al., 2018) on the effect mixed wettability surfaces in flow boiling of water, it was shown that hydrophobic stripes, regardless of their direction with respect to the flow direction, provided active nucleation sites. They also concluded that merging and confinement of the bubbles are the major mechanisms enhancing boiling heat transfer. In another study, Kim et al. (Kim et al., 2020) proved that compared to dotted patterns, parallel patterns possessed a better heat transfer performance at low water mass fluxes, while the dotted surfaces outperformed the parallel patterns at high mass fluxes.

Flow boiling is one of the most effective heat transfer methods, especially in micro-scale and could provide a better performance relative to pool boiling as well as single phase flows (Saraceno et al., 2012). Amongst working fluids, the dielectric coolant FC-72 was proposed as a candidate in flow boiling (Kandlikar, 2010). The working coolant FC-72 is a colorless, odorless and nonflammable fluid with thermal and chemical stability. It also has a low toxicity and good compatibility with metals and plastics (Ma and Chung, 2001). Mudawar et al. (Gersey and Mudawar, 1992) conducted subcooled flow boiling experiments with FC-72. They observed that the boiling phenomenon delayed with the flow velocity. Hiendel et al. (Heindel et al., 1992) conducted flow boiling experiments on FC-72 and revealed that heat transfer was enhanced with the fluid velocity for partially developed boiling. However, for fully developed boiling, the effect of velocity was not significant. According to another study with FC-72, the increase in the fluid velocity and subcooling temperature led to reduced temperature excursion and boiling hysteresis (Samant and Simon, 1989). Martin-Callizo et al. (Martín-Callizo et al., 2007) concluded that even though the heat transfer coefficient generally increased with the heat flux, there was not any dependency for vapor qualities lower than 0.5 .

Bubble dynamics study under reduced gravity in flow boiling experiments with FC-72 conducted by Ma and Chung (Ma and Chung, 2001) revealed that the departure time and size decreased with the flow rate. In another study, Yin et al. (Yin et al., 2000) performed flow boiling tests with R134a and demonstrated that the departure size and frequency decreased with liquid subcooling. Maurus et al. (Maurus et al., 2002) concluded that bubble nucleation increased and decreased with the heat flux and mass flux, respectively. Also, the same trend existed for bubble growth rate.

So far, even though pool boiling heat transfer on purposefully modified surfaces has been investigated by many researchers, flow boiling on biphilic surfaces needs further studies. In this regard, this article is the first study, which focuses on biphilic surfaces fabricated with a new method, on flow boiling of FC-72. Although this fluid has wide industrial applications, the information regarding flow boiling is relatively insufficient. The applied polymer, $\mathrm{C}_{4} \mathrm{~F}_{8}$, possesses hydrophobic properties, and its islands constitute the hydrophobic part of the surface. The heat transfer performance and visualization were investigated for different biphilic surfaces in the following sections. It should be noted that since the hydrophobic surfaces typically provide higher heat transfer coefficients (Choi et al., 2011; Phan et al., 2011; Kim and Lee, 2019; Zhao et al., 2021), the heat transfer coefficients obtained from the biphilic surfaces are compared with a hydrophobic surface, which acts as a better reference in this study for comparison purposes.

\section{EXPERIMENTAL SET-UP, PROCEDURE, AND DATA REDUCTION}

\section{Experimental Set-Up and Test Section}

Figure 1 represents the schematic of the closed loop experimental setup used in this study. The components used in this experimental setup consist of a micropump, a flow meter, the test section, a condenser, temperature and pressure sensors, and a reservoir. The test section, which is shown in Figure 1B, consists of an aluminum block enclosed by the Teflon part to reduce heat losses during experiments. Furthermore, in order to measure the pressure and temperature at the inlet and outlet of the test section, two different small reservoirs were designed. The test specimens and a transparent cover are the other parts used in the test section. The aluminum base can house eight heating cartridges, each having a length of $65 \mathrm{~mm}$ and a diameter of $6 \mathrm{~mm}$. The test samples were placed in the designed area with dimensions of $51.0 \mathrm{~mm} \times 15 \mathrm{~mm}$. The depth of the channel is $1 \mathrm{~mm}$. Before placing the samples, the designed area was treated with a thermal paste to minimize the contact thermal resistance between the test sample and the aluminum block. The Plexiglas, sealed with a sandwich mechanism, was used for further visualization access. The local temperatures and heat fluxes were acquired under steady state conditions, which were collected by the data acquisition system. 

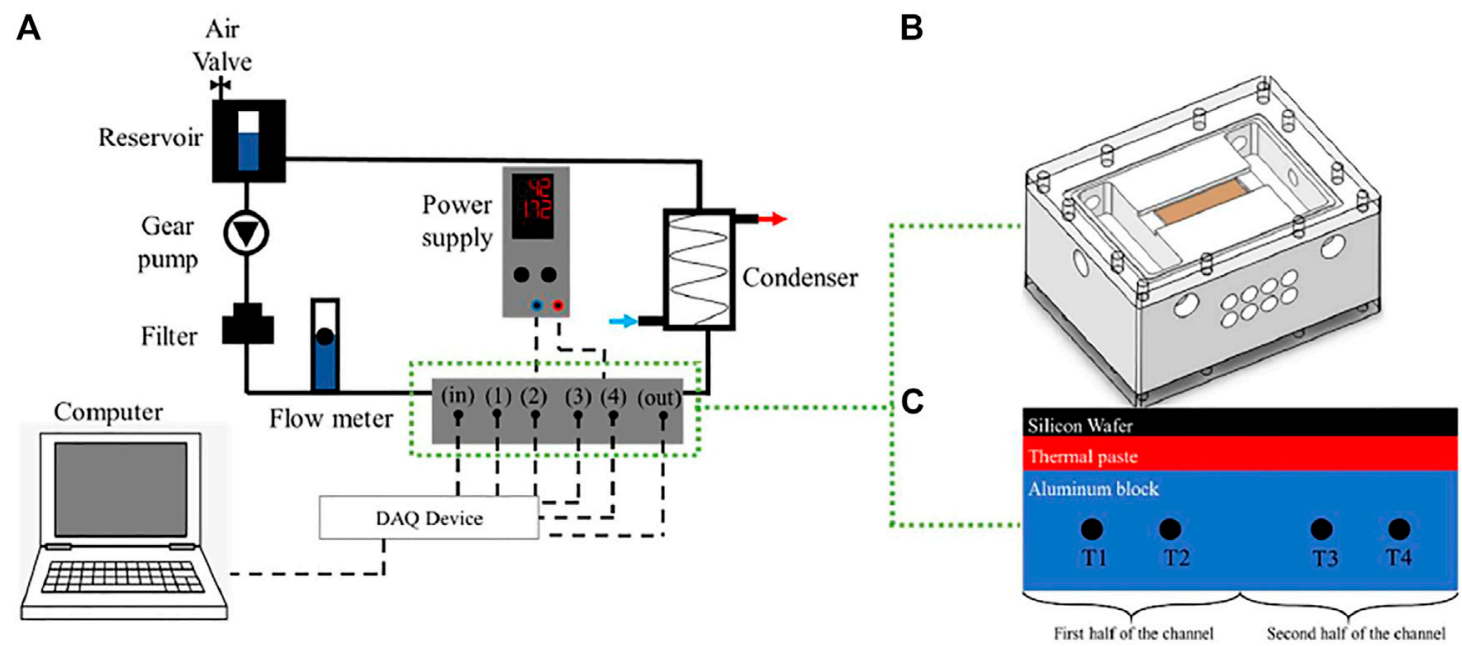

FIGURE 1 | Schematic of (A) closed loop setup (B) test section (C) thermocouple locations.

TABLE 1 | Physical properties of FC-72 and water.

\begin{tabular}{lcc}
\hline Properties & FC-72 & Water \\
\hline Boiling temperature $(1 \mathrm{~atm})$ & $56^{\circ} \mathrm{C}$ & $100^{\circ} \mathrm{C}$ \\
Liquid density $\left(25^{\circ} \mathrm{C}\right)$ & $1680 \mathrm{~kg} / \mathrm{m}^{3}$ & $997 \mathrm{~kg} / \mathrm{m}^{3}$ \\
Vapor density (boiling temperature) & $13.24 \mathrm{~kg} / \mathrm{m}^{3}$ & $0.59 \mathrm{~kg} / \mathrm{m}^{3}$ \\
Surface tension $\left(25^{\circ} \mathrm{C}\right)$ & $0.0105 \mathrm{~N} / \mathrm{m}$ & $0.0720 \mathrm{~N} / \mathrm{m}$ \\
Liquid specific heat & $1.1 \mathrm{~kJ} / \mathrm{kg} \mathrm{K}$ & $4.13 \mathrm{~kJ} / \mathrm{kg} \mathrm{K}$ \\
Latent heat of vaporazation $\left(25^{\circ} \mathrm{C}\right)$ & $88 \mathrm{~kJ} / \mathrm{kg}$ & $2442 \mathrm{~kJ} / \mathrm{kg}$ \\
Liquid thermal conductivity $\left(25^{\circ} \mathrm{C}\right)$ & $0.057 \mathrm{~W} / \mathrm{m} \cdot \mathrm{K}$ & $0.606 \mathrm{~W} / \mathrm{m} \mathrm{K}$ \\
Liquid viscosity $\left(25^{\circ} \mathrm{C}\right)$ & $0.64 \mathrm{mPa} \mathrm{s}$ & $0.89 \mathrm{mPa} \mathrm{s}$ \\
\hline
\end{tabular}

\section{Experimental Procedure}

FC-72 was used as the working fluid in the experiments. The main physical properties of this fluid are summarized in Table 1. During the experiments, two different mass fluxes were provided by the gear pump. During the experiments, the inlet temperature was kept at $28 \pm 1^{\circ} \mathrm{C}$. The data acquired from the experimental test section was under steady state conditions. The average values of temperatures provided by the first and second thermocouple locations were considered to calculate the average temperature of the first half of the surface (Figure 1C). Similarly, the third and fourth thermocouple locations were used to measure the average surface temperature at the second half of the channel. In order to ensure the repeatability of the tests, each test was repeated for at least three times. The average values of the experiments were used in the data reduction part.

\section{Data Reduction}

During the experiments, the obtained voltage, current, and temperature data were reduced to obtain heat transfer coefficient. The mass flux $G$ was calculated as:

$$
G=\frac{\dot{m}}{A_{c}}
$$

Here, $\dot{m}$ is the mass flow rate $(\mathrm{kg} / \mathrm{s})$, and $A_{c}$ is the cross-sectional area of the microchannel $\left(\mathrm{m}^{2}\right)$. Moreover, the measured voltage and current values during the experiments were used to obtain the applied power as:

$$
P=V . I
$$

where $P$ is the applied power $(\mathrm{W})$, and $V$ and Iare the measured voltage (V) and current (A), respectively. Considering that some percentage of the applied power was lost, the heat flux applied to the surface was calculated as:

$$
q^{\prime \prime}=\frac{\left(P-\dot{Q}_{\text {loss }}\right)}{A_{s}}
$$

Here, $\dot{Q}_{\text {loss }}$ is the heat loss, and $A_{s}$ is the area of the heated surface. $\dot{Q}_{\text {loss }}$ was calculated from single phase flow heat transfer. In doing so, single phase FC-72 is introduced to the test section and the inlet and outlet temperatures were measured. Considering that the mass flow rate and specific heat of the working fluid were known, the heat-loss was obtained as:

$$
Q_{\text {loss }}=P-\dot{m} c_{p}\left(T_{\text {out }}-T_{\text {in }}\right)
$$

Using the curve fit technique, the heat losses were estimated at higher temperatures. The heat transfer coefficient (HTC) was found as:

$$
h=\frac{q^{\prime \prime}}{\left(T_{w}-T_{f}\right)}
$$

where $T_{W}$ is the temperature of the heated surface $\left({ }^{\circ} \mathrm{C}\right)$, and $T_{f}$ is the temperature of the working fluid $\left({ }^{\circ} \mathrm{C}\right)$. In order to calculate the temperature at the surface $\left(T_{W}\right)$, the temperature measured at the jth location of temperature measurement and the calculated heat fluxes were used as follows:

$$
T_{w, j}=T_{j}-q^{\prime \prime}\left(\frac{L_{A l}}{K_{A l}}+R_{P}+\frac{L_{S i}}{K_{S i}}\right)
$$

Here, $T_{w, j}$ is the temperature of the substrate at the jth location ( $\mathrm{j}$ $=1-4), T_{j}$ is the temperature read from the jth thermocouple 
TABLE 2 | Uncertainty parameters and analysis

\begin{tabular}{lc}
\hline Parameter & Uncertainty \\
\hline Voltage & $\pm 1 \mathrm{~V}$ \\
Current & $\pm 0.01 \mathrm{~A}$ \\
Temperature & $\pm 0.1 \mathrm{~K}$ \\
Mass flow rate & $\pm 5 \%$ \\
Hight of the channel & $\pm 15 \mu \mathrm{m}$ \\
Heat transfer coefficient & $\pm 7 \%$
\end{tabular}

location. Moreover, $L_{A l}$ and $L_{S i}$ are the thickness of aluminum and silicon samples, respectively, while $K_{A l}$ and $K_{S i}$ are their thermal conductivities. Furthermore, $R_{P}$ is the thermal resistance of the thermal paste.

For subcooled boiling experiments, the fluid temperature was calculated via the energy balance equation (equation 5). Since the pressure drop is not substantial (less than $1 \mathrm{kPaPa}$ ), the saturation temperature is assumed to be constant along the channel. Considering constant heat flux applied to the system, the temperature of the fluid could be obtained as:

$$
\begin{array}{ll}
T_{f, x}=T_{i}+\frac{q^{\prime \prime} \cdot A_{x}}{\dot{m} c_{p}} & T_{f, x}<T_{\text {sat }} \\
T_{f, x}=T_{\text {sat }} & T_{f, x} \geq T_{\text {sat }}
\end{array}
$$

Here, $T_{i}$ is the inlet temperature $\left({ }^{\circ} \mathrm{C}\right)$, and $c_{p}$ is the specific heat capacity of the fluid (J.kg- $\left.1^{\circ} \mathrm{C}-1\right)$. Moreover, $A_{x}$ is the heated area starting from the inlet to the point of interest. Using the uncertainty analysis proposed by Coleman and Steel (Coleman and Steele, 2018), the maximum uncertainty in the HTC was found as $\pm 7 \%$ (Table 2 ).

\section{Validation}

In order to make sure that the experimental setup works properly and the obtained results are reliable, single-phase heat transfer tests were performed to validate the setup. First, the heat flux was applied, and the temperatures were measured at the inlet and outlet of the test section. Meanwhile, the temperature at the different locations of the surface was measured. Considering the obtained temperatures at the inlet and outlet, the heat transfer to the fluid was calculated as: $\dot{Q}=m \dot{c}_{p}\left(T_{\text {out }}-T_{\text {in }}\right)$. Later on, the average heat transfer coefficient was obtained as:

$$
h=\frac{\dot{Q}}{\mathrm{~A}\left(T_{\text {wall }}-T_{f}\right)}
$$

where $T_{f}$ and $T_{\text {wall }}$ are the average temperatures of the fluid and surface, respectively. Considering that the heat transfer coefficient was known, the Nusselt number was calculated as $N u=h D_{H} / k$, where $D_{H}$ and $k$ are the hydraulic diameter of the channel and heat conductivity of the fluid, respectively. The obtained Nusselt numbers were compared with the correlations provided by Shah and London (Shah and London, 2014):

$$
\begin{array}{ll}
N u=1.953\left(\operatorname{Re} \cdot \operatorname{Pr} \cdot D_{H} / L\right)^{1 / 3} & \text { where, }\left(\operatorname{Re} \cdot \operatorname{Pr} \cdot D_{H} / L\right) \geq 33.3 \\
N u=4.364+0.0722\left(\operatorname{Re} \cdot \operatorname{Pr} \cdot D_{H} / L\right) & \text { where, }\left(\operatorname{Re} \cdot \operatorname{Pr} \cdot D_{H} / L\right)<33.3
\end{array}
$$

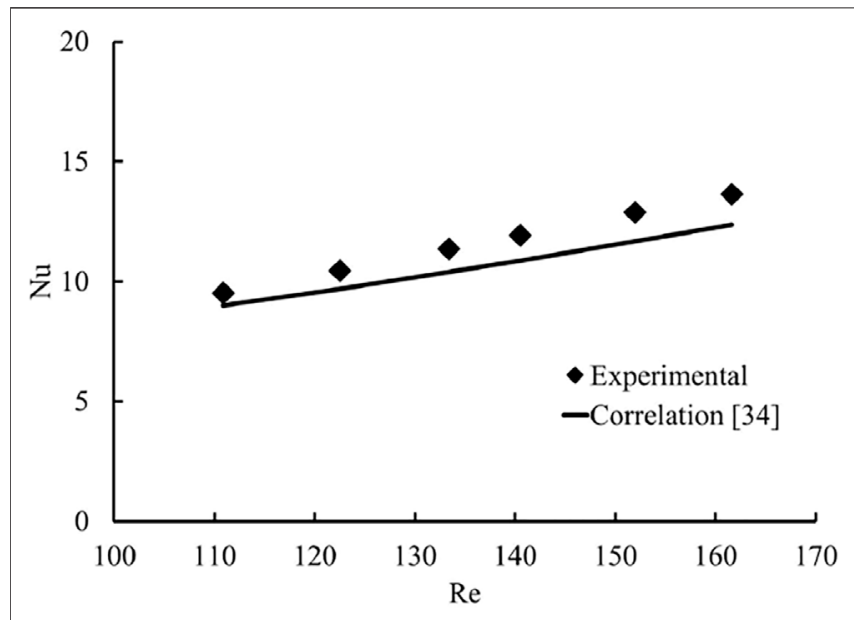

FIGURE 2 | Validation of the experimental setup.

The comparison of the results is presented in Figure 2. As seen in the figure, the obtained experimental results are in good agreement with the predictions of the correlation.

\section{Sample Preparation}

Plasma Polymerization has attracted much attention during the recent years, particularly due to changes in surface wettability (Iqbal et al., 2019; Falde et al., 2016; Siow et al., 2015), which can be performed at both subatmospheric (Sadaghiani et al., 2017) and atmospheric (Park et al., 2017) pressures. Plasma Polymerization offers methods to change the surface geometric and chemistry structures for manipulating the wettability of surfaces (Feng et al., 2002). This ability has motivated many researchers in the field of two-phase heat transfer (Bertossi et al., 2015; Çıkım et al., 2014; Elkholy and Kempers, 2020). Similarly, as mentioned before, $\mathrm{C}_{4} \mathrm{~F}_{8}$ polymer was used in the fabrication of biphilic surfaces. In this innovative fabrication method, different steps were carried out. Firstly, the silicon wafers were washed with Acetone, Isopropanol and DI water, and then $\mathrm{N}_{2}$ gas was blown on the substrate to get rid of any contaminations. Next, in plasma environment (Oxford PlasmaLab System 100 ICP 300 Deep RIE), the wafers were deposited with $\mathrm{C}_{4} \mathrm{~F}_{8}$ polymer (Figure 3A Step I). During this process, the pressure, RF power, ICP power, and deposition temperature were $30 \mathrm{mTorr}, 5 \mathrm{Watt}, 1500 \mathrm{Watt}$, and $5^{\circ} \mathrm{C}$, respectively. Also, the plasma polymerization occurred under the continuous wave $(\mathrm{CW})$. It should be noted that this machine was usually used for etching of semiconductors, including both etching and deposition steps. However, the etching process was deactivated over this fabrication method. After having the fully polymer-coated substrates, a layer of AZ 4562 photoresist (PR) was coated on the silicon substrates at 4,000 rpm for $45 \mathrm{~s}$ and was baked for $1 \mathrm{~min}$ at $110^{\circ} \mathrm{C}$. Even though coating of photoresist on hydrophobic surfaces seems to be challenging, the process did not face any failure. However, a layer of $\mathrm{SiO}_{2}$ could be used as a sacrificial layer for photoresist coating (Zhang et al., 2017). The next step was the UV light exposure $\left(115 \mathrm{~mJ} / \mathrm{cm}^{2}\right)$ using a mask aligner UV-Lithography (Midas aligner) (Figure 3A Step II). Next, by taking advantage of the designed acetate masks, the 


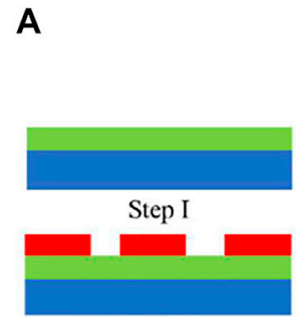

Step IV

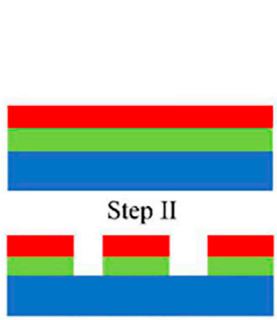

Step V

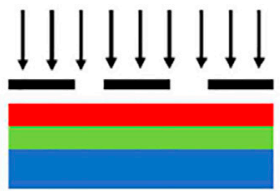

Step III

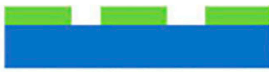

Step VI

Silicon $\quad \mathrm{C}_{4} \mathrm{~F}_{8}$ Polymer $\square$ Mask $\square$ Photoresist (PR)

C
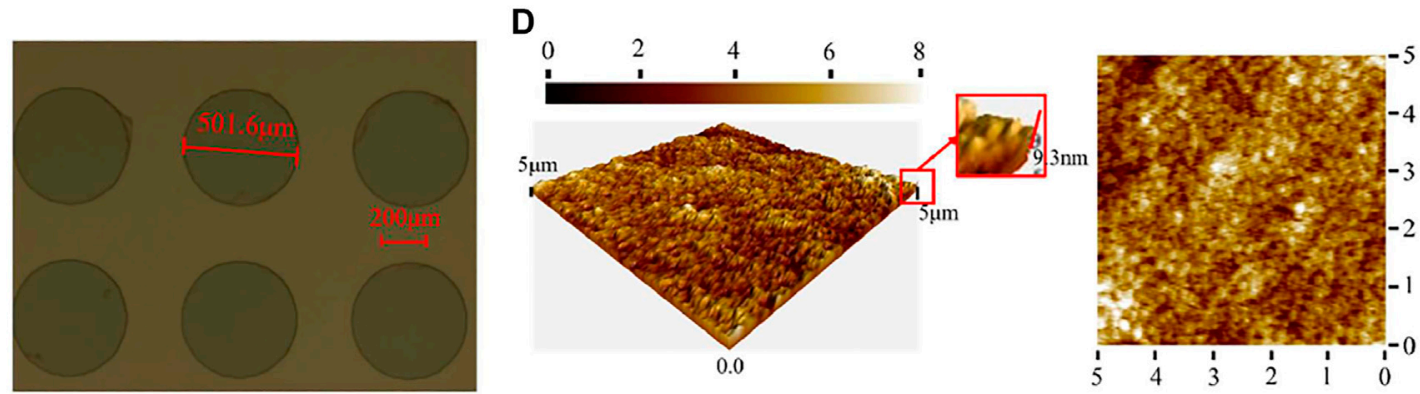

FIGURE 3 | (A) schematic of the fabrication process, (B) microscopic view of the fabricated surfaces, (C) macroscopic representation of the $\mathrm{C}_{4} \mathrm{~F}_{8}$ islands on the silicon surface, (D) AFM images of the coated $\mathrm{C}_{4} \mathrm{~F}_{8}$.

A Hydrophobic
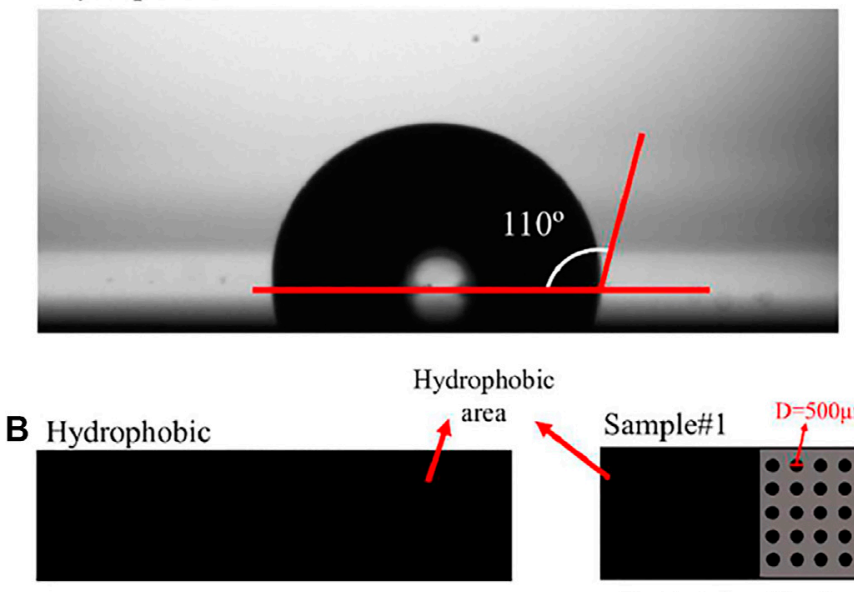

C i)

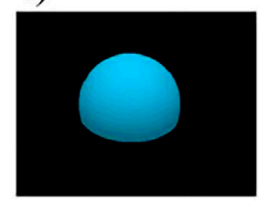

ii)

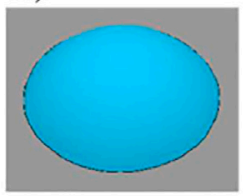

iii)

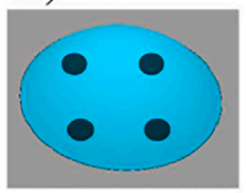

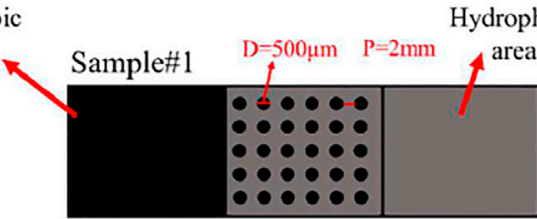

Region I Region II Region III
B

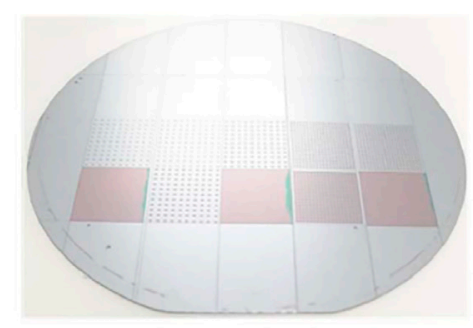

Hydrophilic

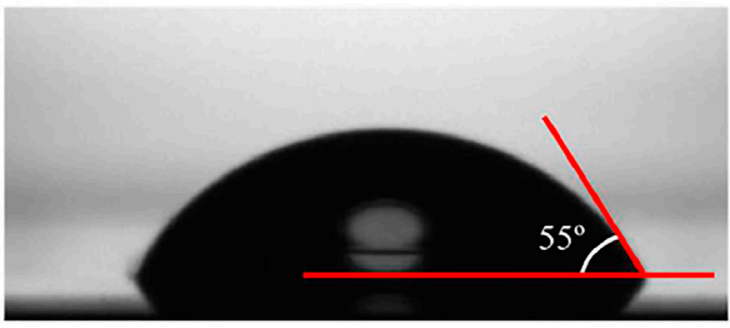

iv)
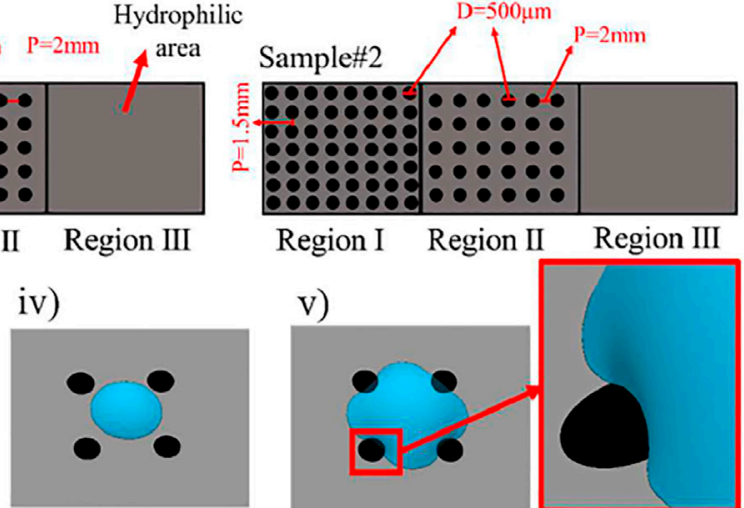

Region I Region II Region III

v)

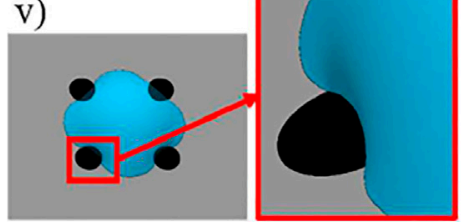

FIGURE 4 | (A) Contact angles of hydrophobic $\left(\mathrm{C}_{4} \mathrm{~F}_{8}\right)$ and hydrophilic (Silicon) parts (B) schematic representations of Sample\#1 and Sample\#2 (C) different scenarios for droplets regarding contact angles. 
TABLE 3 | Characteristics of the tested samples

\begin{tabular}{llll}
\hline & \multicolumn{1}{c}{ Region I } & \multicolumn{1}{c}{ Region II } & Region III \\
\hline Sample 1 & Hydrophobic & Biphilic $-D=500 \mu \mathrm{m}$ & Hydrophilic \\
& & $P=2000 \mu \mathrm{m}$ & \\
Sample 2 & Biphilic-D $=500 \mu \mathrm{m}$ & $\begin{array}{l}\text { Biphilic }-\mathrm{D}=500 \mu \mathrm{m} \\
\end{array}$ & Hydrophilic \\
& $\mathrm{P}=1500 \mu \mathrm{m}$ & $\mathrm{P}=2000 \mu \mathrm{m}$ &
\end{tabular}

wafers were patterned using the photolithography fabrication method (Figure 3A Step III). Afterwards, the AZ 726 MIF developer was used to develop the substrates for $40 \mathrm{~s}$ before putting them on the hot plate. In this step the patterning process was finished, and the areas to be hydrophobic were covered with PR, which was resistant against etching (Figure 3A Step IV). The silicon wafers were put in the Oxford ICP-RIE machine again to etch the polymer until reaching to the silicon areas (Figure 3A Step V). Finally, the substrate shown in Figure 3A Step VI is obtained. Figure 3B shows the macroscopic view of the fabricated surfaces, which were fabricated on a six-inch silicon wafer. The bright areas of the wafer are the silicon areas, while the darker regions correspond to the $\mathrm{C}_{4} \mathrm{~F}_{8}$ polymer areas. Moreover, in order to display the quality of the coated polymer, a microscopic analysis of the wafer is attached. As seen in Figure 3C, the tolerance of hydrophobic spots is smaller than $2 \mu \mathrm{m}$.

The roughness of a substrate significantly affects the obtained heat transfer coefficient (Dong et al., 2014; Shojaeian and Koşar, 2015). To ensure that any possible enhancement in heat transfer does not stem from the roughness of the coated polymer, the roughness of the surfaces was measured using $2 \mathrm{D}$ and $3 \mathrm{D}$ Atomic Force Microscopy (AFM) in dynamic mode (ezAFM, Nanomagnetics Instruments). The AFM images are provided in Figure 3D. According to the obtained results, the average roughness of the surfaces was $0.87 \mathrm{~nm}$, while the root mean square was obtained as $1.11 \mathrm{~nm}$. It is noteworthy to mention that the contact angles of a $5 \mu \mathrm{L}$ water droplet on the silicon and the $\mathrm{C}_{4} \mathrm{~F}_{8}$ islands were $55^{\circ}$ and $110^{\circ}$, respectively, as depicted in Figure 4.a. Furthermore, Figure 4B shows the configurations of the tested samples. As shown in Figure 4B, the biphilic samples are divided into three regions including fully hydrophobic, biphilic, and fully hydrophilic surfaces. Table 3 summarizes the characteristics of the tested substrates. It should be noted that the biphilic surfaces do not necessarily change the contact angle of the droplet but the hydrophobic spots provide potential nucleation sites. When a droplet is placed on a tested surface, different scenarios could occur. In order to have a better understanding of the contact angles, some simulations were made using the Surface Evolver 1.30 software. The results are presented in Figure 4C. Upon placing a droplet on a totally hydrophobic or totally hydrophilic surface, an agreement in the contact angles with the measured contact angles could be seen (Figures 4C-i and ii, respectively). However, when a droplet is placed on the biphilic regions, the shape of the triple contact line depends on the size of the droplet. A large droplet $(25 \mu \mathrm{L}$ in Figure 4C-iii) has a larger size than the hydrophobic areas, which results in a contact angle almost the same as a totally hydrophilic surface. Similarly, a small droplet, which could fit inside the hydrophobic spots ( $5 \mu \mathrm{L}$ in Figure $4 \mathrm{C}$-iv), has a contact angle almost the same as the totally hydrophilic sample. However, the contact lines of a droplet with a medium size $(15 \mu \mathrm{L}$ in Figure 4Cv) include the both hydrophilic and hydrophobic regions. In this case, the contact line on the hydrophobic areas is repelled towards the center of the droplet.

\section{RESULT AND DISCUSSION}

In this section, the obtained results from the flow boiling experiments, which cover both heat transfer and visualization results, are presented. For the experiments, the applied heat flux ranged from $2 \mathrm{~W} / \mathrm{cm}^{2}$ and $16 \mathrm{~W} / \mathrm{cm}^{2}$. Moreover, two different mass fluxes of $90 \mathrm{~kg} / \mathrm{m}^{2} \mathrm{~s}$ and $130 \mathrm{~kg} / \mathrm{m}^{2} \mathrm{~s}$ were considered. The obtained HTCs along along with the boiling curves are depicted in Figure 5, 6. In both Figures, the results shown on the right side and left side represent the data obtained for the first and second halves of the channel, respectively. Later on, the visualization results are discussed and compared with the obtained results from a previous study, where water was used as the working fluid (Ahmadi et al., 2020).

As shown in Figure 5 at a mass flux of the $90 \mathrm{~kg} / \mathrm{m}^{2} \mathrm{~s}$, both biphilic surfaces show a better performance compared with the entirely uniform hydrophobic surface in terms of boiling HTC. At the first half of the channel, the obtained results suggest that at heat fluxes lower than $5 \mathrm{~W} / \mathrm{cm}^{2}$ the biphilic surfaces have no significant influence compared to their hydrophobic counterpart. This result stems from the reason that at the mentioned heat fluxes boiling does not ensue. As can be inferred from the boiling curves (Figure 5) for heat fluxes lower than $5 \mathrm{~W} / \mathrm{cm}^{2}$, the wall superheats obtained for different surfaces are close to each other. However, as the heat flux increases from $5 \mathrm{~W} / \mathrm{cm}^{2}$ to $12 \mathrm{~W} / \mathrm{cm}^{2}$, the biphilic surfaces yields higher HTCs compared to the hydrophobic surface. The higher HTC is due to nucleation sites provided by the hydrophobic islands. Sisman et al. (Şişman et al., 2016) showed that an increase in density of nucleation sites could decrease HTC. They concluded that close nucleation sites might result in sudden coalescence of bubbles. The sudden coalescence, in turn, results in extending the thermal boundary layer of the bubble beyond the stability limit. Therefore, the corresponding nucleation site is canceled, and a temporal condensation might occur inside the bubble. The hydrophobic islands are not relatively close in this study to result in cancelations of the nucleation sites. Moreover, it should be noted that surface $\# 2$, due to the biphilicity at the entrance region, exhibits a slightly better performance than surface\#1. At the heat fluxes higher than the $12 \mathrm{~W} / \mathrm{cm}^{2}$, all surfaces have HTCs close to each other. Regarding the subcooling of the working fluid at the inlet part along with the high temperature of the surfaces under this condition, all the surfaces provide almost the same numbers of nucleation sites, which result in HTCs close to each other.

Similar to the first half, biphilic surfaces have better performances compared to the hydrophobic surface at the second half of the channel (Figure 5). At heat fluxes lower than $9 \mathrm{~W} / \mathrm{cm}^{2}$, the average HTCs for the biphilic surfaces are significantly higher than the hydrophobic surface. As mentioned 

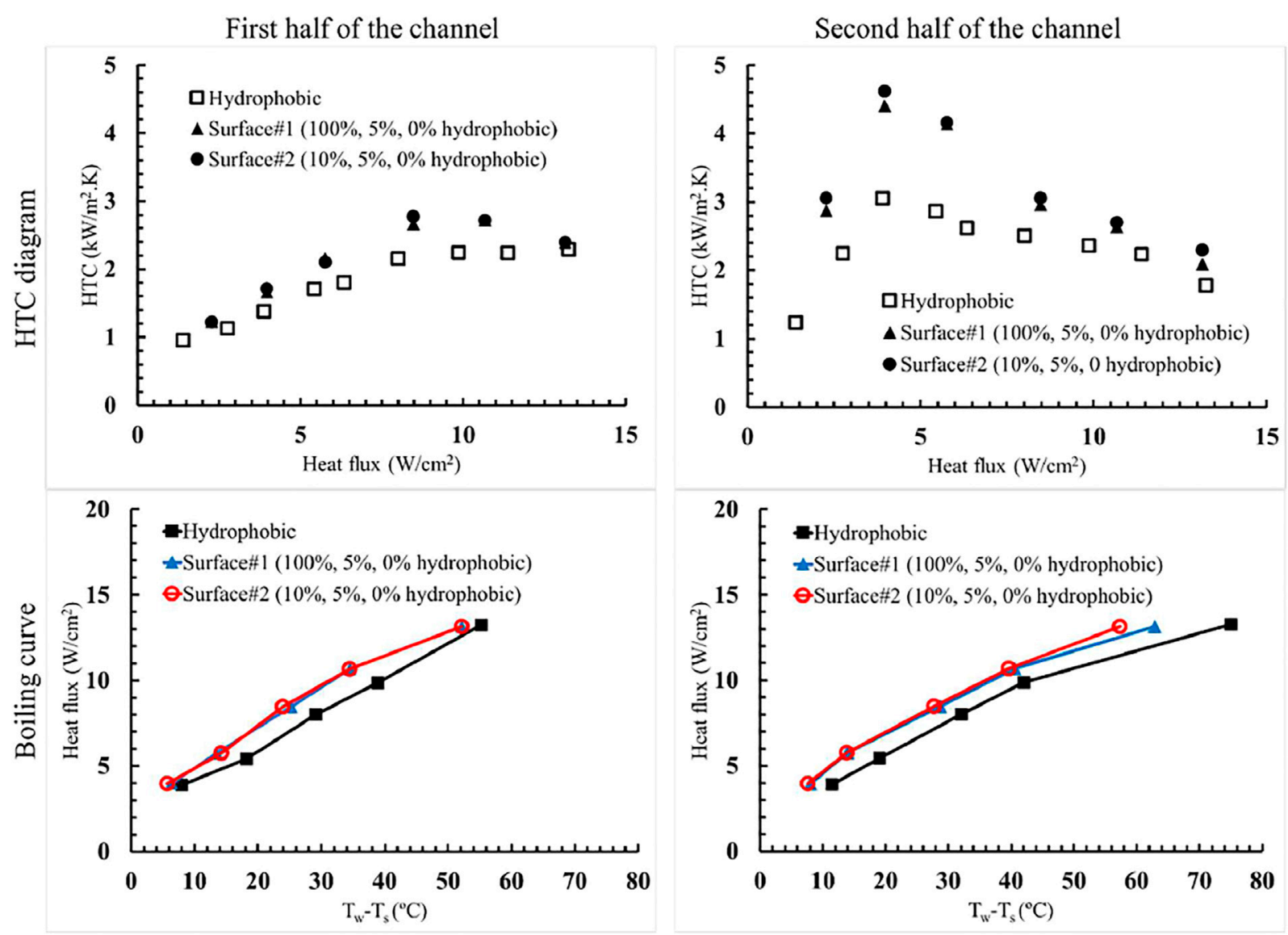

FIGURE 5 | Heat transfer coefficients (HTCs) and boiling curves corresponding to the mass flux of $90 \mathrm{~kg} / \mathrm{m}^{2} \mathrm{~s}$.

before, along the first half of the channel, at heat fluxes lower than $5 \mathrm{~W} / \mathrm{cm}^{2}$, the performances of all surfaces are similar. However, at the second half, considering that the subcooled fluid mainly reaches the saturation temperature during the first half of the channel along with the nucleation points provided by the hydrophobic islands, higher HTCs are obtained. Moreover, as the heat flux is raised to values higher than $9 \mathrm{~W} / \mathrm{cm}^{2}$, due to partial dry out of the surfaces, all surfaces exhibit similar behavior. The wall superheats on surface\#2 is lower than surface\# 1 at the applied heat flux of $14 \mathrm{~W} / \mathrm{cm}^{2}$, while they correspond to similar HTCs at lower heat fluxes. The presence of biphilic islands at the region\# 1 of surface\# 1 delay the dryout condition at high heat fluxes. At the mentioned mass flux, the maximum enhancement was more than $50 \%$ compared to the hydrophobic surface and was reached at the heat flux of $4 \mathrm{~W} / \mathrm{cm}^{2}$.

The results regarding HTCs at the mass flux of $130 \mathrm{~kg} / \mathrm{m}^{2} \mathrm{~s}$ are displayed in Figure 6. At the first half of the channel, as the boiling is not initiated at low heat fluxes, the biphilic surfaces lead to the almost same heat transfer coefficients compared to their hydrophobic counterpart, as they have almost the same wall superheats. This trend is the same for the previously mentioned mass flux for heat fluxes lower than $5 \mathrm{~W} / \mathrm{cm}^{2}$. Lie et al. (Lie et al., 2007) reported that the required heat flux for the onset of nucleation increases with the mass flux. This phenomenon explains the delay in the transition of the dominant heat transfer mechanism from single-phase to phase-change, as the mass flux increases. At heat fluxes higher than $9 \mathrm{~W} / \mathrm{cm}^{2}$, since the nucleation points are visible on the hydrophobic islands, biphilic surfaces have a better performance than the wholly hydrophobic surface. As shown in boiling curves of Figure 6, the wall superheats obtained for surface\#2 are smaller than surface\#1, which implies that the hydrophobic islands at the entrance region of surface\#2 lead to a slight difference in heat transfer.

In contrast to the mass flux of $90 \mathrm{~kg} / \mathrm{m}^{2} \mathrm{~s}$, where the phasechange heat transfer was dominant for all the heat fluxes at the second half of the channel, at the heat fluxes lower than $4 \mathrm{~W} / \mathrm{cm}^{2}$, single-phase heat transfer is the dominant heat transfer mechanism since boiling does not incept at these heat fluxes along the channel, and as depicted, the wall superheats are close to each other, and all the surfaces exhibit similar HTCs at heat fluxes lower than $4 \mathrm{~W} / \mathrm{cm}^{2}$. However, as the heat flux increases, the HTCs of the biphilic surfaces strongly deviate from the hydrophobic surface. It should be noted that the tested surfaces have a maximum enhancement of $26 \%$ with respect to the hydrophobic surface, which happens at the heat flux of $9 \mathrm{~W} / \mathrm{cm}^{2}$. 

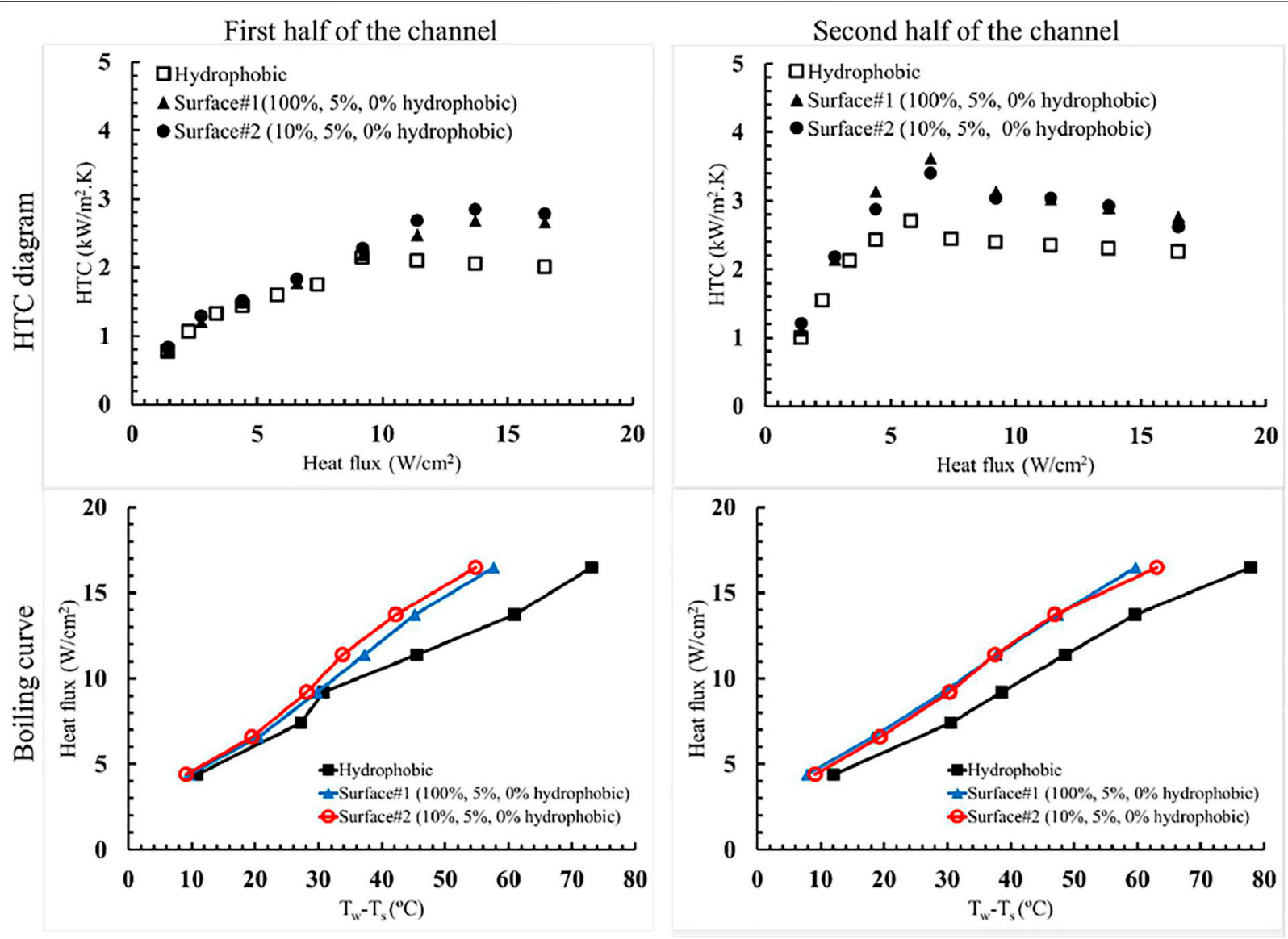

FIGURE 6 | Heat transfer coefficients (HTCs) and boiling curves corresponding to the mass flux of $130 \mathrm{~kg} / \mathrm{m}^{2} \mathrm{~s}$.

The results regarding the visualization are presented in Figure 7, for the mass flux of $90 \mathrm{~kg} / \mathrm{m}^{2} \mathrm{~s}$. As seen in Figure 7, the surface conditions strongly affect the bubble dynamics inside the channel. At the heat flux of $5 \mathrm{~W} / \mathrm{cm}^{2}$, at the first half of the channel, the hydrophobic surface and surface\#1 have almost single-phase flow conditions. However, the hydrophobic islands on the entrance region of surface\#2 result in the generation of bubbles, since the hydrophobic islands provide active nucleation sites. According to the heat transfer results in Figure 5, these nucleation points are not capable of increasing the HTC noticeably. At the second half of the channel, however, the generated bubbles strongly affect HTC. As seen in Figure 7, on the totally hydrophobic surface, the coalescence of the bubbles results in larger bubbles, and transition from bubbly flow regime to slug-flow (heat flux of $7 \mathrm{~W} / \mathrm{cm}^{2}$ ). However, on both biphilic surfaces, slug flow cannot be observed.

In our previous study (Ahmadi et al., 2020), we reported that one of the reasons for HTC enhancement in the biphilic surfaces could be due to bubble break-up during the slug-flow regime, rather than their coalescence. The obtained results of this study are in agreement with the previous study. As shown in Figure 8, the coalescence of small bubbles on the hydrophobic surface results in an elongated bubble. However, on the biphilic surface, where the hydrophobic islands provide potential nucleation points, the generated bubbles are relatively close. Moreover, the bubbles are generated on previously designed islands and are well dispersed. These generated bubbles in turn block the effective cross-sectional area, and the velocity of the working fluid will be higher at the remaining cross-section area (shown by red arrows in Figure 8) The higher velocity gradient results in a higher shear force applied to the bubbles. Considering that the bubbles remain intact as long as the shear force is smaller than its surface tensional counterpart (Sun et al., 2017), the higher shear force results in break-up of the bubbles on biphilic surfaces and prevents effective coalescence of the bubbles. It should be noted that in our previous study, water was used as the working fluid and the slug flow regime was observed on both hydrophobic and biphilic surfaces. However, since the surface tension of FC-72 fluid is much smaller than water and there exists a larger distance between nucleation sites, the bubbles tend to break up on biphilic surfaces easier than the bubbles in the case of water.

At higher heat fluxes $\left(\mathrm{q}>9 \mathrm{~W} / \mathrm{cm}^{2}\right)$, both surface\#1 and surface\#2 provide larger number of nucleation sites than the totally hydrophobic surface. Compared to surface\#1, the larger amount of designated nucleation sites at the inlet part of surface\#2 increases the number of generated bubbles. As can be seen in Figure 5, this results in a slightly better performance of surface\#2 with respect to surface\#1. 

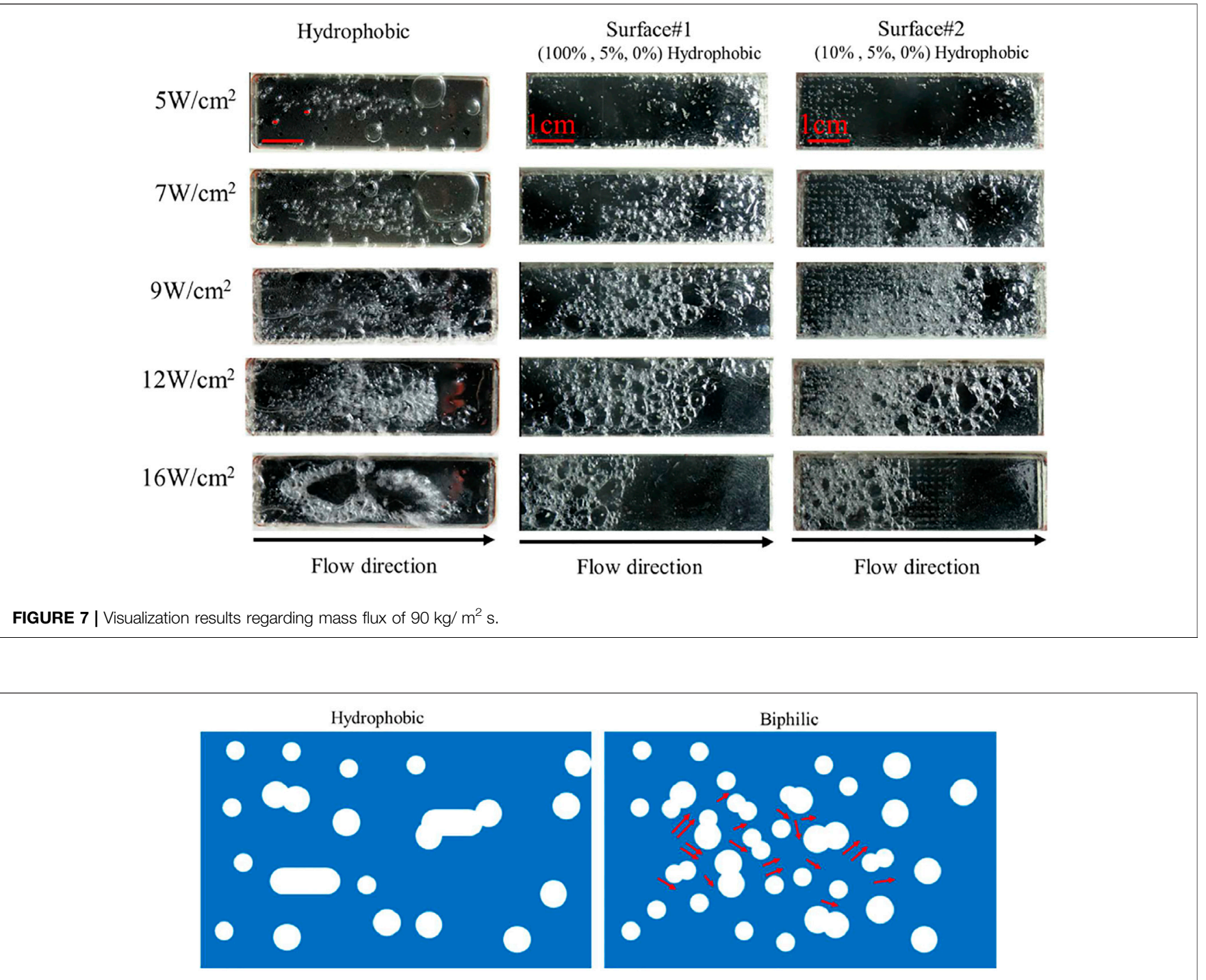

FIGURE 8 | Comparison of bubble dynamics on the hydrophobic surface with a biphilic surface.

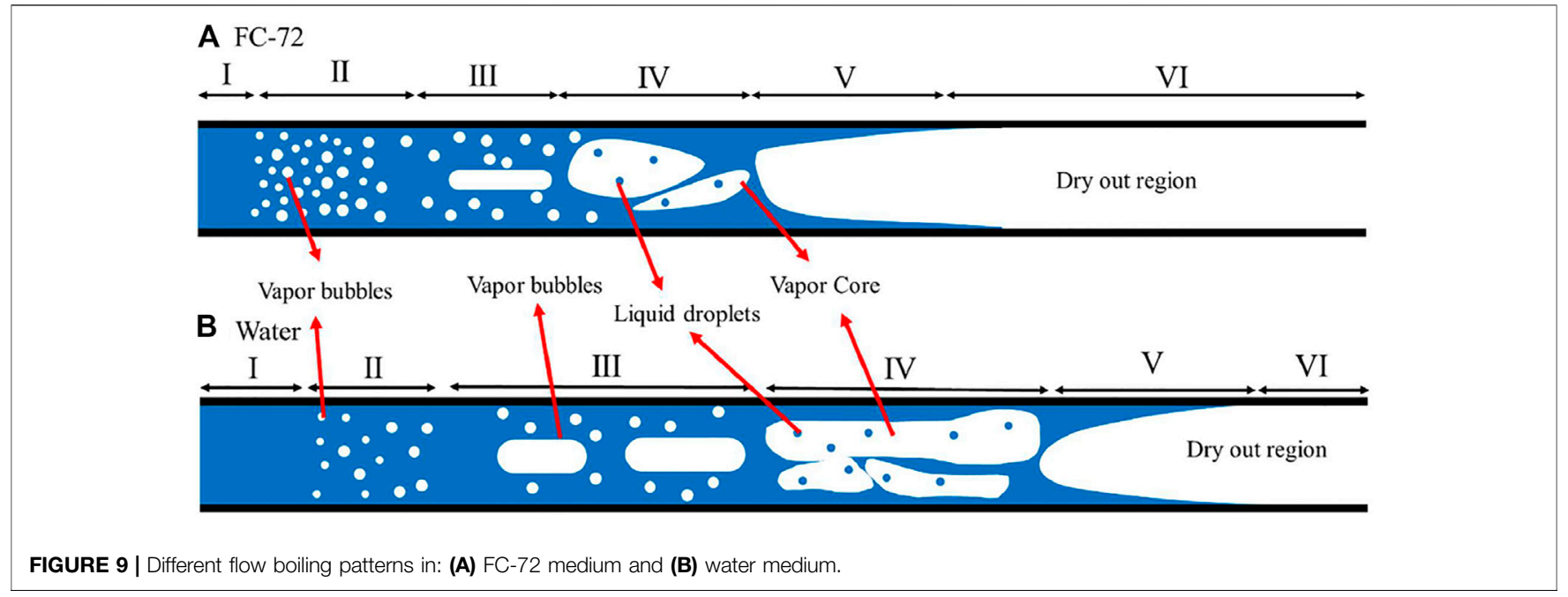


Figure 9 shows the comparison of flow patterns of FC-72 with water. In both the present and previous studies (Ahmadi et al., 2020), since the subcooled liquid is supplied to the channel, boiling does not incept at the first region (Region I). In region II, which is known as the bubbly flow region, the density of the generated bubbles is larger for FC-72 flow compared to water (Ahmadi et al., 2020). This is due to two main reasons. First, the contact angles on the islands fabricated in this study are larger than the previous one $\left(110^{\circ} v s .90^{\circ}\right)$. Second, the latent heat of vaporization of FC-72 is smaller than water, and a larger amount of vapor is generated and observed at a fixed heat flux in the present study. Moreover, it should be noted that since FC-72 has a higher density and a smaller surface tension in comparison with water, a larger drag force and a smaller surface tension force are present. Therefore, the generated bubbles in FC-72 detach within a shorter time with respect to water. In other words, the frequency of bubble generation in FC-72 is smaller than that in water. Regarding these differences, the duration of bubbly flow regime in FC-72 is extended in comparison with water.

Region III represents the slug flow regime. Considering that break-up of a bubble occurs whenever the applied shear force becomes larger than its surface tension counterpart, the size of elongated bubbles generated from FC-72 is relatively smaller than bubbles generated from water vapor, due to the smaller surface tension of FC-72 compared with water. Moreover, slug flow in water is the dominant flow pattern in water, while bubbly flow is the dominant flow regime in FC-72. In region IV (known as churn flow regime), generally, the middle of the channel is blocked by the vapor core. Similar to slug flow regime, the lower surface tension of FC-72 results in a smaller vapor core in comparison with water. It should be noted that in churn flow regime, the density of the liquid core in FC-72 is higher than water, since FC-72 is more wettable than water.

\section{CONCLUSION}

This study investigates the effect of surface mixed wettability on flow boiling of FC-72 in a rectangular minichannel. The surfaces, including two biphilic surfaces and one hydrophobic surface, were fabricated and tested at the mass fluxes of $90 \mathrm{~kg} / \mathrm{m}^{2} \mathrm{~s}$ and $130 \mathrm{~kg} /$ $\mathrm{m}^{2} \mathrm{~s}$ and heat fluxes ranging from $1 \mathrm{~W} / \mathrm{cm}^{2}$ to $16 \mathrm{~W} / \mathrm{cm}^{2}$. The main conclusions driven from this study are as follows:

\section{REFERENCES}

Aboubakri, A., Yanik, C., Akkuş, Y., Koşar, A., and Sadaghiani, A. K. (2020). Numerical and Experimental Investigation on Evaporation of Water Droplet on Surfaces with Mixed Wettability. Int. Conf. Nanochannels, Microchannels, Minichannels vol. ASME 2020 18th, V001T06A002, 2020. ASME 2020 18th International Conference on Nanochannels, Microchannels, and Minichannels collocated with the ASME 2020 Heat Transfer Summer Conference and the ASME 2020 Fluids Engineering Division Summer Meeting. doi:10.1115/icnmm2020-105510.1115/ ICNMM2020-1055[Online]. Available:
- Surface mixed wettability is an effective method for BHT enhancement especially effective for coolants with smaller surface tension and latent heat of vaporization. The effect of biphilicity on such coolants are more dominant at the second half of the channel.

- The main mechanisms in heat transfer enhancement with FC-72 are the uniform distribution of nucleation sites on the superheated surface and the bubble break-up in the channel.

- Biphilic surfaces could provide enhancements in flow boiling heat transfer up to $50 \%$ compared to the wholly hydrophobic surface.

- The surface with hydrophobic islands at the inlet region of the channel shows slightly better performance in terms of BHT compared to the surface with a hydrophobic entrance.

The obtained results of this study prove that the biphilic surfaces are promising candidates of modified surfaces in high heat flux cooling with flow boiling.

\section{DATA AVAILABILITY STATEMENT}

The raw data supporting the conclusions of this article will be made available by the authors, without undue reservation.

\section{AUTHOR CONTRIBUTIONS}

Conceptualization, VA, AA, SC, AS, KS, and AK; investigation, VA, S.C. and AA; methodology, VA, AA, and AS; supervision, KS and AK; validation, VA, AA, and AS; writing (original draft preparation), VA, AA, AS, and AK; writing (review and editing), AS, KS, and AK. All authors have read and agreed to the published version of the manuscript.

\section{FUNDING}

This study was funded by the Scientific and Technological Research Council of Turkey (TUBITAK) and Royal Academy of Engineering through the 1601-Bilateral Newton-Katip celebi Cooperation Programme-Project number: 4180047.

Ahmadi, V. E., Aboubakri, A., Sadaghiani, A. K., Sefiane, K., and Koşar, A. (2020). Effect of Functional Surfaces with Gradient Mixed Wettability on Flow Boiling in a High Aspect Ratio Microchannel. Fluids 5 (4), 239. doi:10.3390/fluids5040239

Ahmadi, V. E., and Erden, H. S. (2020). A Parametric CFD study of computer room air handling bypass in air-cooled data centers. Appl. Therm. Eng. 166, 114685. doi:10.1016/j.applthermaleng.2019.114685

Ahmadi, V. E., and Erden, H. S. (20182018). Investigation of CRAH bypass for aircooled data centers using computational fluid dynamics in IEEE International Telecommunications Energy Conference (INTELEC) (New Jersey: IEEE), 1-6.

Basu, N., Warrier, G. R., and Dhir, V. K. (2002). Onset of nucleate boiling and active nucleation site density during subcooled flow boiling. J. Heat Transfer 124 (4), 717-728. doi:10.1115/1.1471522 
Bertossi, R., Caney, N., Gruss, J. A., and Poncelet, O. (2015). Pool boiling enhancement using switchable Polymers coating. Appl. Therm. Eng. 77, 121-126. doi:10.1016/j.applthermaleng.2014.11.061

Chehrghani, M. M., Abbasiasl, T., Sadaghiani, A. K., and Koşar, A. (2021). CopperBased Superhydrophobic Nanostructures for Heat Transfer in Flow Condensation. ACS Appl. Nano Mater. 4 (2), 1719-1732. doi:10.1021/ acsanm.0c03181

Choi, C., Shin, J. S., Yu, D. I., and Kim, M. H. (2011). Flow boiling behaviors in hydrophilic and hydrophobic microchannels. Exp. Therm. Fluid Sci. 35 (5), 816-824. doi:10.1016/j.expthermflusci.2010.07.003

Çıkım, T., Armağan, E., Ozaydin Ince, G., and Koşar, A. (2014). Flow boiling enhancement in microtubes with crosslinked pHEMA coatings and the effect of coating thickness. J. Heat transfer 136 (8), 081504.

Coleman, H. W., and Steele, W. G. (2018). Experimentation, validation, and uncertainty analysis for engineers. New Jersey: John Wiley \& Sons.

Dai, X., Yang, F., Yang, R., Huang, X., Rigdon, W. A., Li, X., et al. (2014). Biphilic nanoporous surfaces enabled exceptional drag reduction and capillary evaporation enhancement. Appl. Phys. Lett. 105 (19), 191611. doi:10.1063/ 1.4901962

Dong, L., Quan, X., and Cheng, P. (2014). An experimental investigation of enhanced Pool boiling heat transfer from surfaces with micro/nanostructures. Int. J. Heat Mass Transfer 71, 189-196. doi:10.1016/ j.ijheatmasstransfer.2013.11.068

Elkholy, A., and Kempers, R. (2020). Enhancement of Pool boiling heat transfer using 3D-Printed Polymer fixtures. Exp. Therm. Fluid Sci. 114, 110056. doi:10.1016/j.expthermflusci.2020.110056

Falde, E. J., Yohe, S. T., Colson, Y. L., and Grinstaff, M. W. (2016). Superhydrophobic materials for biomedical applications. Biomaterials 104, 87-103. doi:10.1016/j.biomaterials.2016.06.050

Feng, L., Li, S., Li, Y., Li, H., Zhang, L., Zhai, J., et al. (2002). Super-Hydrophobic Surfaces: From Natural to Artificial. Adv. Mater. 14 (24), 1857-1860. doi:10.1002/adma.200290020

Florio, L. A., and Harnoy, A. (2007). Combination technique for improving natural convection cooling in electronics. Int. J. Therm. Sci. 46 (1), 76-92. doi:10.1016/ j.ijthermalsci.2006.03.007

Gersey, C. O., and Mudawar, I. (1992). Effects of Orientation on Critical Heat Flux From Chip Arrays During Flow Boiling. ASME. J. Electron. Packag. 114 (3), 290-299. doi:10.1115/1.2905453

Hashemi, M., and Noie, S. H. (2017). Study of flow boiling heat transfer characteristics of critical heat flux using carbon nanotubes and water nanofluid. J. Therm. Anal. Calorim. 130 (3), 2199-2209. doi:10.1007/s10973017-6661-1

Heindel, T. J., Ramadhyani, S., and Incropera, F. P. (1992). Liquid Immersion Cooling of a Longitudinal Array of Discrete Heat Sources in Protruding Substrates: II-Forced Convection Boiling. ASME. J. Electron. Packag. 114 (1), 63-70. doi:10.1115/1.2905443

Honda, H., Takamastu, H., and Wei, J. J. (2002). Enhanced boiling of FC-72 on silicon chips with micro-pin-fins and submicron-scale roughness. J. Heat Transfer 124 (2), 383-390. doi:10.1115/1.1447937

Honda, H., and Wei, J. (2004). Enhanced boiling heat transfer from electronic components by use of surface microstructures. Exp. Therm. Fluid Sci. 28 (2-3), 159-169. doi:10.1016/s0894-1777(03)00035-9

Iqbal, M., Dinh, D. K., Abbas, Q., Imran, M., Sattar, H., and Ul Ahmad, A. (2019). Controlled surface wettability by Plasma Polymer surface modification. Surfaces 2 (2), 349-371. doi:10.3390/surfaces 2020026

Kandlikar, S. G. (2010). Scale effects on flow boiling heat transfer in microchannels: A fundamental Perspective. Int. J. Therm. Sci. 49 (7), 1073-1085. doi:10.1016/ j.ijthermalsci.2009.12.016

Kim, J., Cho, J. Y., and Lee, J. S. (2020). Flow boiling enhancement by bubble mobility on heterogeneous wetting surface in microchannel. Int. J. Heat Mass Transfer 153, 119631. doi:10.1016/j.ijheatmasstransfer.2020.119631

Kim, J., and Lee, J. S. (2019). Numerical study on the effects of inertia and wettability on subcooled flow boiling in microchannels. Appl. Therm. Eng. 152, 175-183. doi:10.1016/j.applthermaleng.2019.02.064

Kim, J. M., Kim, T., Yu, D. I., Noh, H., Kim, M. H., Moriyama, K., et al. (2018). Effect of heterogeneous wetting surface characteristics on flow boiling Performance. Int. J. Heat Fluid Flow 70, 141-151. doi:10.1016/ j.ijheatfluidflow.2018.02.006
Lie, Y., Ke, J., Chang, W., Cheng, T., and Lin, T. (2007). Saturated flow boiling heat transfer and associated bubble characteristics of FC-72 on a heated micro-pin-finned silicon chip. Int. J. Heat Mass Transfer 50 (19-20), 3862-3876. doi:10.1016/j.ijheatmasstransfer.2007.02.010

Ma, Y., and Chung, J. N. (2001). A study of bubble dynamics in reduced gravity forced-convection boiling. Int. J. Heat mass transfer 44 (2), 399-415. doi:10.1016/s0017-9310(00)00106-X

Martín-Callizo, C., Palm, B., and Owhaib, W. (2007). Subcooled flow boiling of R$134 \mathrm{a}$ in vertical channels of small diameter. Int. J. Multiphase Flow 33 (8), 822-832. doi:10.1016/j.ijmultiphaseflow.2007.02.002

Maurus, R., Ilchenko, V., and Sattelmayer, T. (2002). Study of the bubble characteristics and the local void fraction in subcooled flow boiling using digital imaging and analysing techniques. Exp. Therm. Fluid Sci. 26 (2-4), 147-155. doi:10.1016/s0894-1777(02)00121-8

Motezakker, A. R., Sadaghiani, A. K., Çelik, S., Larsen, T., Villanueva, L. G., and Koşar, A. (2019). Optimum ratio of hydrophobic to hydrophilic areas of biphilic surfaces in thermal fluid systems involving boiling. Int. J. Heat Mass Transfer 135, 164-174. doi:10.1016/j.ijheatmasstransfer.2019.01.139

Park, C.-S., Jung, E., Kim, D., Kim, D., Lee, H.-K., Shin, B., et al. (2017). Atmospheric Pressure Plasma Polymerization synthesis and characterization of Polyaniline films doped with and without iodine. Materials 10 (11), 1272. doi: $10.3390 / \mathrm{ma} 10111272$

Phan, H. T., Caney, N., Marty, P., Colasson, S., and Gavillet, J. (2011). Flow boiling of water in a minichannel: The effects of surface wettability on two-phase Pressure drop. Appl. Therm. Eng. 31 (11-12), 1894-1905. doi:10.1016/j.applthermaleng.2011.02.036

Sadaghiani, A. K., Altay, R., Noh, H., Kwak, H. J., Şendur, K., Misırlığlu, B., et al. (2020). Effects of bubble coalescence on Pool boiling heat transfer and critical heat flux - A Parametric study based on artificial cavity geometry and surface wettability. Int. J. Heat Mass Transfer 147, 118952. doi:10.1016/ j.ijheatmasstransfer.2019.118952

Sadaghiani, A. K., Rajabnia, H., Çelik, S., Noh, H., Kwak, H. J., Nejatpour, M., et al. (2020). Pool boiling heat transfer of ferrofluids on structured hydrophilic and hydrophobic surfaces: The effect of magnetic field. Int. J. Therm. Sci. 155, 106420. doi:10.1016/j.ijthermalsci.2020.106420

Sadaghiani, A. K., Saadi, N. S., Parapari, S. S., Karabacak, T., Keskinoz, M., and Koşar, A. (2017). Boiling heat transfer Performance enhancement using micro and nano structured surfaces for high heat flux electronics cooling systems. Appl. Therm. Eng. 127, 484-498. doi:10.1016/j.applthermaleng.2017.08.018

Samant, K. R., and Simon, T. W. (1989). Heat Transfer from a Small Heated Region to R-113 and FC-72. ASME. J. Heat Transfer 111 (4), 1053-1059. doi:10.1115/ 1.3250767

Saraceno, L., Celata, G. P., Furrer, M., Mariani, A., and Zummo, G. (2012). Flow boiling heat transfer of refrigerant FC-72 in microchannels. Int. J. Therm. Sci. 53, 35-41. doi:10.1016/j.ijthermalsci.2011.11.007

Shah, R. K., and London, A. L. (2014). Laminar flow forced convection in ducts: a source book for compact heat exchanger analytical data. New Jersey: Academic press.

Shojaeian, M., and Koşar, A. (2015). Pool boiling and flow boiling on micro- and nanostructured surfaces. Exp. Therm. Fluid Sci. 63, 45-73. doi:10.1016/ j.expthermflusci.2014.12.016

Siow, K. S., Kumar, S., and Griesser, H. J. (2015). Low-Pressure Plasma Methods for Generating Non-reactive Hydrophilic and Hydrogel-like Bio-Interface Coatings - A Review. Plasma Process. Polym. 12 (1), 8-24. doi:10.1002/ ppap. 201400116

Şişman, Y., Sadaghiani, A. K., Khedir, K. R., Brozak, M., Karabacak, T., and Koşar, A. (2016). Subcooled flow boiling over microstructured Plates in rectangular minichannels. Nanoscale Microscale Thermophysical Eng. 20 (34), 173-190.

Sun, L., Mo, Z., Zhao, L., Liu, H., Guo, X., Ju, X., et al. (2017). Characteristics and mechanism of bubble breakup in a bubble generator developed for a small TMSR. Ann. Nucl. Energ. 109, 69-81. doi:10.1016/j.anucene.2017.05.015

Tan, K., Hu, Y., and He, Y. (2021). Effect of wettability on flow boiling heat transfer in a microtube. Case Stud. Therm. Eng. 26, 101018. doi:10.1016/j.csite.2021.101018

Wang, H., Yang, Y., He, M., and Qiu, H. (2019). Subcooled flow boiling heat transfer in a microchannel with chemically Patterned surfaces. Int. J. Heat Mass Transfer 140, 587-597. doi:10.1016/j.ijheatmasstransfer.2019.06.027

Yin, C.-P., Yan, Y.-Y., Lin, T.-F., and Yang, B.-C. (2000). Subcooled flow boiling heat transfer of R-134a and bubble characteristics in a horizontal annular duct. 
Int. J. Heat mass transfer 43 (11), 1885-1896. doi:10.1016/s0017-9310(99) 00278-1

Zhang, H., Yan, Q., Xu, Q., Xiao, C., and Liang, X. (2017). A sacrificial layer strategy for Photolithography on highly hydrophobic surface and its application for electrowetting devices. Sci. Rep. 7 (1), 3983-3987. doi:10.1038/s41598-01704342-Z

Zhao, Q., Qiu, J., Zhou, J., Lu, M., Li, Q., and Chen, X. (2021). Visualization study of flow boiling characteristics in open microchannels with different wettability. Int. J. Heat Mass Transfer 180, 121808. doi:10.1016/j.ijheatmasstransfer.2021.121808

Conflict of Interest: The authors declare that the research was conducted in the absence of any commercial or financial relationships that could be construed as a potential conflict of interest.
Publisher's Note: All claims expressed in this article are solely those of the authors and do not necessarily represent those of their affiliated organizations, or those of the publisher, the editors and the reviewers. Any product that may be evaluated in this article, or claim that may be made by its manufacturer, is not guaranteed or endorsed by the publisher.

Copyright $\odot 2021$ Aboubakri, Ahmadi, Celik, Sadaghiani, Sefiane and Kosar. This is an open-access article distributed under the terms of the Creative Commons Attribution License (CC BY). The use, distribution or reproduction in other forums is permitted, provided the original author(s) and the copyright owner(s) are credited and that the original publication in this journal is cited, in accordance with accepted academic practice. No use, distribution or reproduction is permitted which does not comply with these terms. 